\title{
LA DICTADURA BRASILERA EN LOS GOBIERNOS DE CORTE DEMOCRÁTICO A PARTIR DE LA GUERRA FRÍA.
}

The brazilian dictatorship in democratic government cut from the cold war.

\author{
Autores: Guadalupe Gómez García ${ }^{1}$ \\ Correspondencia: ggomez1@unisimonbolivar.edu.co
}

\begin{abstract}
RESUMEN
El presente artículo de revisión tiene como finalidad reconocer el actual panorama de la política mundial donde se descubren dinámicas de estilos de gobierno que como en el caso de América Latina han tenido influencias cuyas acciones se enmarcan desde periodos anteriores, en los cuales se soportó en la mayoría de los países de esta parte del mundo un sistema fundamentado es una gobernanza de corte dictatorial, que subsiste al interior de un sistema democrático. Ello implica una mirada al panorama internacional de la política y la economía que ha sido afrontada por estas naciones, bajo la influencia de los gobiernos sacudidos por la dictadura. En este panorama internacional se hace referencia s a un estilo de gobierno que como el de Brasil, considerado como la primera nación de América Latina, hoy es sacudida y cuestionada en el ámbito mundial por la forma como conduce su gobernanza.
\end{abstract}

\section{Palabras Clave}

Dictadura, Democracia, Gobernanza, Política, Economía, Guerra Fría.

\section{ABSTRACT}

This reflection article aims to review the current situation of world politics where you will discover dynamic style of government as in the case of Latin America have had influences whose actions fall from previous periods, in which he endured on the most countries in this part of the world a grounded system is a dictatorial governance, which subsists within a democratic system. This implies a look at the international arena of politics and the economy that has been faced by these nations under the influence of governments rocked

\footnotetext{
${ }^{1}$ Abogada. Especialista en Derecho Laboral. Magíster en Derecho Administrativo de la Universidad Simón Bolívar de Barranquilla Docente Programa de Derecho Barranquilla de la Universidad Simón Bolívar.
} 
by the dictatorship. In this international panorama s reference to a style of government that like Brazil, considered the first nation in Latin America, today is shaken and questioned at the global level by the way is leading its governance.

keywords

Dictatorship, Democracy, Governance, Politics, Economy, Cold War

\section{INTRODUCCION}

En el marco de la política mundial aparecen variadas y diferentes dinámicas en las gobernanzas contemporáneas. En el caso de América Latina han existido en los diferentes países, influencias políticas y económicas que en periodos anteriores al actual sistema democrático que se observa en algunos países, lo cual implica una mirada al panorama internacional de la política y la economía que afrontan estas naciones, bajo la influencia de los gobiernos sacudidos por la dictadura. En este panorama internacional se hace referencia a un estilo de gobierno que como el de Brasil, que es considerada como la primera nación de América Latina, hoy es afectada y cuestionada en el ámbito mundial por la forma como conduce la gobernanza. Tal situación propone el siguiente interrogante ¿cómo se ha presentado la dictadura brasilera en los gobiernos de corte democrático a partir de la guerra fría?

El presente artículo propone como objetivo general describir cómo se ha presentado la dictadura brasilera en los gobiernos de corte democrático a partir de la guerra fría. Y como objetivos específicos revisar los antecedentes en el sistema de Gobierno de la Republica Federativa del Brasil; revisar de qué forma se implementó la dictadura como sistema de gobierno en el Brasil y estudiar cómo surgió la Democracia Brasilera en términos de Valores Humanos. 
Vol.7, No 1. Diciembre de 2015 pp. 208 -235

Es supremamente importante el estudio desarrollado porque la mirada a las gobernanzas y la forma como los gobiernos actúan y condicionan el panorama político y económico desde sus actitudes y acciones proporcionar en los asociados de cada país y en el plano internacional, malestar que de una u otra forma afecta a las demás naciones del orbe; basta con mostrar las protestas y movilizaciones en Brasil, Chile y Colombia - para situar algunos ejemplos-, de la magnitud de la situación.

\section{MÉTODO}

El artículo parte de las lecturas y análisis realizados a la bibliografía suministrada en el Doctorado en Ciencias Políticas, fundamentalmente a las que contienen información relacionada con la incidencia de la Guerra Fría en América Latina y los antecedentes en el sistema de gobierno de la República Federativa del Brasil, y los aspectos relacionados con las doctrinas de seguridad nacional en este país.

Los análisis hechos a esta información fueron consignados en fichas de trabajo conocidas como Reseñas Analíticas Estructuradas RAE, las cuales fueron posteriormente vinculadas en cada uno de los puntos que contiene el Artículo.

1. Antecedentes en el sistema de gobierno de la República Federativa del Brasil

1.1. Los pormenores del encuentro 
El encuentro entre diferentes mundos ocurrido en el año de 1500 como resultado de una expedición portuguesa liderada por Pedro Alvares Cabral da cuenta de un importante hallazgo: por un lado, la selva brasilera y por el otro lado, un proyecto científico de navegación ${ }^{2}$. El imperio portugués que se inició a partir del siglo XV gracias a la era de los descubrimientos, con la figura principal de Enrique el Navegante ${ }^{3}$, y a su visión de hacer de Portugal una potencia marítima que se encargaría de adelantar el comercio con el resto del mundo, merece elogios, pero también comentarios de rechazo, puesto que si los portugueses inventaron herramientas útiles como el astrolabio, una nueva embarcación llamada la carabela, el concepto de los meridanos y paralelos, para medir las distancias recorridas o existentes (un sistema de líneas imaginarias de la superficie terrestre representado en la cuadricula de un mapa), crear factorías que eran ciertos establecimientos instalados en las colonias, dedicados al comercio, y otras invenciones consideradas de igual trascendencia, fueron utilizadas con el interés de expandir su dominio por el resto del mundo, tanto conocido como el que "estaba descubriendo".

Un año antes (1494), se firma el Tratado de Tordecillas ${ }^{4}$, entre la monarquía hispánica y el reino de Portugal, en la provincia del mismo nombre (hoy provincia perteneciente a Valladolid) el cual se constituye el primer reparto del

\footnotetext{
${ }^{2}$ Abramo, Alcione. Grandes Personagens da Nossa História (v.1). São Paulo: Abril Cultural, 1969. (en portugués)

${ }^{3}$ EcuRed. Enrique el Navegante. Disponible en: http://www.ecured.cu/Enrique_el_Navegante Consultado el 22 de junio de 2016.

${ }^{4}$ Historia universal. Disponible en: http://www.historiacultural.com/2010/04/tratado-de-tordesillas.html. Consultado el 22 de junio de 2016.
} 
mundo, con respecto a zona de navegación y conquista del Océano Atlántico mediante una línea imaginaria que evitara los conflictos de intereses. Este Tratado permitió a Portugal la asignación del territorio de lo que en ese tiempo era Brasil.

Cuando los portugueses se encontraron con la población brasilera les llamó la atención los exuberantes bosques llenos de madera y entre ellos, un árbol de color rojizo como braza encendida por su tonalidad, a quien los exploradores portugueses le dieron el nombre de palo-Brasil, del cual se extraía una tintura con lo que se teñía la ropa y servía para la exportación a gran escala. Con la exportación se hizo crecer la economía en la región y en la zona. En este encuentro de dos mundos, también a Portugal se les aparece el oro y a los pobladores nativos del Brasil, de buenas a primeras, se le aparece un imperio ${ }^{5}$.

\subsection{El imperio}

Brasil se encuentra dividida en los siguientes periodos generales, los cuales se describen a continuación:

- La precolombina hasta cuando se dio "el descubrimiento" (1500)

- Brasil como colonia entre 1500 y 1822

- El imperio entre 1822 y 1889

- La Vieja República (1889-1930)

- La Era de Getulio Vargas (1930-1945)

- La República Nova (1945-1964)

- La dictadura militar (1964-1985)

${ }^{5}$ Sanfuentes Echeverría, O. (2006). Europa y su percepción del nuevo mundo a través de las especies comestibles y los espacios americanos en el siglo XVI. Historia (Santiago). 2006, vol.39, n.2 Disponible en: http://www.scielo.cl/scielo.php?script=sci_arttext\&pid=S0717-71942006000200006 Consultado el 25 de junio de 2016 
- La Nueva República (1985) a partir del presente)

Al triunfar la Revolución Francesa y con la coronación de Napoleón Bonaparte como Emperador, se presentó una invasión en el año 1808 a España. Ante tales hechos el Rey Carlos IV renuncia al trono, cediéndoselo a su hijo Fernando con el nombre de Fernando VII, circunstancia que aprovechó Napoleón Bonaparte para reunirse con su familia real en la ciudad de Bayona (Francia), obligando a Carlos IV y a Fernando VII a entregar el trono a su hermano José Bonaparte. En esta forma Napoleón Bonaparte corona como rey de España a su hermano con el nombre de José I y con ello trata de extinguir a los borbones de España 6 .

La invasión de Francia hacia Portugal fue producto del reclamo que hiciese Napoleón Bonaparte a María I de Portugal, adhesión al bloqueo continental ordenado por Napoleón contra Gran Bretaña e incluyera declaración de guerra hacia la isla. Esta situación generó dos opciones fraguadas en Portugal. Una de ellas estaban relacionada con aceptar las exigencias de Napoleón, y la otra se refería a pedir ayuda a Gran Bretaña e irse para el Brasil. Portugal contaba con inferioridad numérica para afrontar una guerra con los franceses, así que decidieron pedir ayuda a Gran Bretaña para que la corte de Lisboa huyera hacia el Brasil. En esta forma Brasil quedó bajo el poder de Portugal y de María I, madre de Juan VI. La corte de Lisboa con cerca de 15.000 persona entre civiles y

\footnotetext{
${ }^{6}$ Bergeon, L.; Furet, F. \& Koselleck, R. (1976). Historia Universal 26. La época de las Revoluciones Europeas 1780-1848. Madrid: Siglo XXI de España.
} 
Vol.7, No 1. Diciembre de 2015 pp. $208-235$

militares, partió para El Brasil el 27 de noviembre de 1808, custodiados por barcos ingleses.

Entre las razones de peso para el traslado del imperio portugués al Brasil son tenidas en cuenta las siguientes:

- Salvar la dinastía

- La legitimidad del trono portugués

- Debían proteger al Brasil que era más grande y rico que Portugal.

1.3. Qué pasó con Portugal?

En definitiva, Portugal se queda solo y se salva como imperio, al igual como dinastía, la legitimación del trono y también logra salvarse de Napoleón. La gente que se quedo en Portugal y muchos comerciantes arribaron a Brasil, quien abre mundo sus puertas para recibir los científicos, y los extranjeros, mientras que en Lisboa se languidece y se pide el regreso del rey que se encontraba en Brasil y mediante una rebelión decide volver a Portugal. Su hijo Pedro quien habría nacido en Brasil y se muestra con un sencillo tropical le propone a su padre que lo deje encargado de dedicarse a reinar en esta región, por lo que el padre acepta el pedido es el él quien se traslada a Portugal.

Con la instauración de la corte en Portugal por Juan VI, este pretende recuperar Brasil como colonia, pero esta - que es más grande que Portugal- va despegando y después de haber sido un imperio no quieren ser colonia de los portugueses. Por lo que Pedro I, el 7 de septiembre de 1823 proclama la 
Vol.7, No 1. Diciembre de 2015 pp. $208-235$

independencia del Brasil $^{7}$, por lo que convoca a una Asamblea Nacional

Constituyente y en el interior de esta se forman dos grupos, en la siguiente forma:

- Un grupo conformado por el partido portugués en el que estaban agrupados únicamente los portugueses

- Otro grupo conformado por el partido brasileño representado por los nativos del Brasil.

En la fecha del 24 de marzo de 1824 se proclama la constitución de 1824, cuya fuente principal la constituye la doctrina constitucional que estaba impregnada por el conservadurismo francés. En el año 1981 se establece la República Federal cuyas características principales son:

- Gobierno presidencial.

- Sufragio masculino universal para todos los brasileros alfabetizados mayores de 21 años.

- Voto descubierto.

1.4. El Imperio de Brasil (1822-1889)

En el año 1823, el Imperio del Brasil en 1823 era notorio que se observase los límites en las Misiones Orientales, los límites con Paraguay antes de la Guerra

\footnotetext{
${ }^{7}$ Gómez Jaramillo, M. (2014). Las Independencias Hispanoamericanas. Perspectivas Historiográficas españolas de 1808 a 1812. Madrid (España): Universidad Carlos III de Madrid. Tesis Doctoral recuperado en: http://earchivo.uc3m.es/bitstream/handle/10016/19042/tesis_marco_gomez\%20_jaramillo.pdf?sequence=1 . Consultado el 25 de junio de 2016
} 
de la Triple Alianza en los ríos Mbotetey e Igurey; el Acre y la Banda Oriental; ésta última ocupada con el nombre de Provincia Cisplatina ${ }^{8}$.

Años anteriores, en 1808, el rey Juan VI de Portugal (que en ese tiempo era príncipe regente), huyendo del ejército de Napoleón I, hizo el trasladó de su asiento de Portugal a Brasil, y con ello dejó de tener estatus colonial y pasó a ser pasó a ser el Reino de Brasil (en ese mismo año de 1808), lo cual la convirtió en parte del Reino Unido de Portugal, Brasil y Algarve siendo la capital efectiva de tal Reino Unido la ciudad de Río de Janeiro. Con el regreso de gran parte de la familia real a Portugal en 1821, se acrecentó el deseo por la independencia entre los brasileños. El 7 de septiembre de 1822, el entonces príncipe-regente proclamó la independencia de Brasil, y fue coronado emperador.

\subsection{La Vieja República (1889-1930)}

El tránsito del Imperio del Brasil a los Estados Unidos del Brasil, ocurrido después del reinado de Pedro II quien fue depuesto el 15 de noviembre de 1889 por un golpe militar republicano liderado por el general Deodoro da Fonseca, quien se convirtió en el primer presidente del país ${ }^{9}$. El país pasó de imperio con el nombre de Estados Unidos del Brasil (que en a su turno en 1967 fue cambiado por el de República Federativa del Brasil). En esta época y hasta el año 1930, el gobierno fue una democracia constitucional, que se caracterizó por una

\footnotetext{
8 Historiaría Universal. El imperio de Brasil. Recuperado en http://mihistoriauniversal.com/edadcontemporanea/imperio-de-brasil/. Consultado el 25 de junio de 2016

${ }^{9}$ Ensayo de América Latina " Brasil". Recuperado en http://yazminalwaysthinkinme.blogspot.com.co/2011/03/ensayo-de-america-latina-brasil.html Consultado el 25 de junio de 2016
} 
Vol.7, No 1. Diciembre de 2015 pp. 208 -235

presidencia que se alternaba entre las facciones dominantes de los Estados de

São Paulo y Minas Gerais. En los últimos años del siglo XIX, se dio un vuelco en la economía brasilera, pues el café comenzó a reemplazar al azúcar como el principal recurso de exportación del país, lo cual proporcionó el crecimiento económico El negocio del café causó que Brasil creciera económicamente, atrayendo a muchos inmigrantes europeos, particularmente de Italia y Alemania. Este influjo de labor también permitió al país desarrollar una economía industrial que se expandió lejos de la costa. Este periodo el cual fue conocido como la Vieja República, culminó en el año 1930 con un golpe militar que colocó a Getulio Vargas, un civil, en la presidencia de la República.

\section{El período de Getulio Dornelles Vargas}

\subsection{Antecedentes y períodos presidenciales}

Getulio Vargas nación en São Borja, el 19 de abril de 1882 - Río de Janeiro, 24 de agosto de 1954, fecha en la cual se encontraba cumpliendo con su cuarto periodo presidencial. Fue un político brasileño cuatro veces presidente de la República de Brasil, los cuales se detallan a continuación ${ }^{10}$ :

- 1930-1934 en el Gobierno Provisorio;

- 1934-1937, en el Gobierno constitucional;

- 1945, en el Estado Novo;

- 1951-1954, Presidente electo por voto directo.

2.2. Era Vargas (1930-1945). Gobierno Provisorio

${ }^{10}$ Koifman, J. Compilador (2001), Presidentes do Brasil, Rio de Janeiro: Editora Rio. 
La junta militar que tomó el control del país en 1930, co9locó a Getúlio

Dorneles Vargas en el poder como presidente provisional. El cambio de régimen contribuyó con la decadencia de la oligarquía cafetera y el ascenso de las clases medias y las oligarquías periféricas. El presidente Vargas gobernó en una forma u otra de manera continuada, salvo en un breve período, hasta su suicidio ocurrido en el año 1954. Bien temprano, y a partir de su primer periodo presidencial (1930), los sucesivos gobiernos permitieron conseguir el crecimiento de la industria y la agricultura y el desarrollo del extenso interior del territorio brasileño.

Getulio Vargas gobernó como Presidente provisional entre 1930 y 1934. Por cuanto rl golpe militar había suspendido la vigencia de la Constitución de 1891, y si bien Vargas había hecho la promesa con la promulgación de una nueva Carta Magna. En julio de 1932 estalló en São Paulo la llamada Revolución Constitucionalista, que exigió la instauración de un régimen constitucional y fue sofocada en octubre. En 1934 se proclamó una nueva Constitución y Getulio Vargas fue elegido presidente por el Congreso. ${ }^{11}$

Los tres años que siguieron fueron definitivamente de una progresiva polarización política, las cuales se materializaron en el aparecimiento de fuerzas y organizaciones izquierdistas como la Alianza Nacional Libertadora o el Partido Comunista Brasileño; también otros movimiento surgieron como el de inspiración fascista denominando Integralismo. En 1935 se produjo el fracaso de una intentona revolucionaria de izquierda encabezada por ciertos sectores del ejército

\footnotetext{
${ }^{11}$ Carone, E. (1974). A república nova, 1930-1937. São Paulo: Difusão Européia do Livro,
} 
Vol.7, No 1. Diciembre de 2015 pp. 208 -235

y algunos individuos ligados a la Unión de Republicas Socialista Soviéticas; poco después los integralistas intentan un putsch. Aprovechando el clima de pánico reinante, el 10 de noviembre de 1937, un año antes de las elecciones presidenciales, Getulio Vargas da un golpe de Estado y se convierte en dictador. El régimen instaurado, de carácter populista, se denominó Estado Novo. El 29 de octubre de 1945, los militares obligan a Vargas a dejar el poder.

Este periodo se caracteriza entre otras actividades y decisiones por el implemento de políticas sociales, cambio a la constitución, aprobación el voto femenino, implementación de la jornada laboral de ocho horas, modernización del Brasil, postmodernización de una sociedad, la aceptación del termino de que existan reglas en materia laboral, derecho en conclusión de reglas de juego, cierre de los partidos políticos, limites a la libertad de expresión, creación de una imaginación del Brasil.

Los Estados nacionales se forjan a través de una serie de mitos, leyendas colectivas de la cultura, en las cuales se pone de acuerdo un pueblo para atribuirse la base de un Estado nacional para compartir. En tal sentido Vargas ataca las oligarquías, limita su poder y lo reparte con el pueblo, no acepta que la oposición y la reforma sociales vengan de ella, infiltró el mundo de los trabajadores, eliminó la oposición y la columna prestex, creó el Estado corporativo. Brasil en ese período era excluyente con la sociedad, por lo que modificó la constitución y creó los estados de excepción. También creó la bandera, la zamba el himno y el futbol brasileros.

2.3. República Nova (1945-1964) 
Ante la renuncia de Vargas en 1945, y después de redactarse una nueva

Constitución en 1946, la cual restauraba los derechos individuales respecto a la anterior, se inicia el período conocido como la República Nova ${ }^{12}$. Este período consistió en un régimen democrático, durante el cual la capital de la República se desplazó de Río de Janeiro a Brasilia y que se caracterizó por el populismo, el nacionalismo y el desarrollismo, combinándose estas denominaciones en forma simultánea.

Se destacan como los principales presidentes de este período a los siguientes: Getúlio Vargas, elegido democráticamente en 1950 y quien gobernó hasta su suicidio en 1954, y Juscelino Kubitschek (1956-1961) ${ }^{13}$. En 1961 fue elegido Jânio Quadros ${ }^{14}$, quien renunció en agosto de ese mismo año. Ejerció como Presidente quien fuera su vicepresidente João Goulart, qel cual se dedicó a acometer una política de reformas sociales, destacándose las maniobras de las oligarquías tradicionales y la CIA quienes gestionaron acciones para provocar su caída. El golpe de Estado de 1964 lo depuso y estableció una dictadura militar represiva.

\section{La implementación de la democracia como sistema de gobierno en El Brasil contrario a la dictadura}

3.1. La Dictadura militar (1964-1985)

\footnotetext{
${ }^{12}$ Fausto, B. (2009). Historia de Brasil. Sao Paulo: Editora da Universidade de Sao Paulo.

${ }^{13}$ Carvalho, L. Gobierno Juscelino Kubitschek, Brasil School. Disponible en

$<$ http://brasilescola.uol.com.br/historiab/juscelino-kubitschek.htm>. Consultado el 30 de junio de 2016.

14 Benevides Mezquita, M.V. (1999).El Gobierno Quadros. 2ª edición Sao Paulo: Brasiliense,
} 
Vol.7, No 1. Diciembre de 2015 pp. 208 -235

Una vez que Juscelino Kubitschek después de esa pujanza y el optimismo aunado al cumulo de logros y ventajas que le dio el Siglo XIX, además del gran impulso que le proporcionó el Siglo XX, Brasil entro en un proceso de crear instituciones democráticas ya que en la época de Getulio Vargas la gente se quejaba porque no representaba una democracia, sino que encarnaba una dictadura, pues muchas de sus acciones eran absolutamente arbitrarias - puede analizarse nociones de arbitrariedad en Mejia Turizo \& Medina Solano (2014) -: Ello dio origen a la formación de partidos políticos y grupos políticos, que poco a poco se fueron institucionalizando hasta lograr representativa en el Estado. Brasil pasó de ser un imperio a una democracia no sin antes constituirse en una república bajo un poder militar muy grande (años 60).

Paradójicamente suele ocurrir que los Estados cuando están creando las instituciones democráticas, debido a que participan múltiples partidos con formas diferentes de participación, estas democracias son terriblemente frágiles e inestables porque están empezando a cimentarse. Tal vulnerabilidad resulta ser nefasta cuando se presenta una crisis de gobernabilidad porque nadie sabe manejar este proceso democrático y hace que se presente una polarización de la sociedad por el contexto internacional que está viviendo en el mundo en ese momento y por las mismas contradicciones que hay en el Brasil debido a la exclusiones de muchas personas en cuanto a que no se les tiene en cuenta en la participación de los proyectos de riqueza; a ello se le agrega la influencia de lo que 
Vol.7, No 1. Diciembre de 2015 pp. $208-235$

está ocurriendo en el mundo lo cual afecta actualmente a Brasil, como resultado de la catástrofe de veinticinco años de dictadura ${ }^{15}$.

El resultado de esta situación tiene su origen en la Guerra Fría, iniciada en Europa con las conferencias de Yalta y Psotan ${ }^{16}$ cuando los Estados Unidos de Norteamérica y la Unión de Repúblicas Soviéticas en zonas de influencias deciden acordar utilizar sus presencia (la segunda en Europa oriental y los primeros sobre la América Latina) en cuanto al equilibrio del terror y esto da como resultado la polarización del mundo. Después de la Revolución china (1949), la guerra fría se traslada al Asia con la presentación de la Guerra de Corea (1951); posteriormente, el escenario de traslada a Cuba, con la conflagración cubana (1959). Esta Guerra Fría en cada escenario se presenta con un rostro diferente: en Europa es la nuclearización de la OTAN y el Pacto de Varsovia, los misiles, el muro de Berlín; en Asia, los espías y el bloqueo en Asia, la política de contención que lleva a la Guerra de Corea y del Vietnam (indochina).

En América Latina la Guerra $\mathrm{Frí}^{17}$ se traduce en términos de las dictaduras, las desapariciones y lo que se considera como un enemigo interno, por cuanto no aparece para el continente americano una doctrina que se llama la "doctrina de la Seguridad Nacional". Lo que plantea esta doctrina es que no existe

\footnotetext{
${ }^{15}$ Marina E. (2014) Brasil: la larga sombra de la dictadura. Recuperado http://www.dw.com/es/brasilla-larga-sombra-de-la-dictadura/a-17532308. consultado 30 de junio de 2016

${ }^{16}$ Conferencias Aliadas durante la Segunda GUERRA Mundial (2007). Recuperado en https://historia1imagen.cl/2007/09/11/conferencias-aliadas-durante-la-segunda-guerra-mudial/ consultado 30 de junio de 2016

${ }^{17}$ Bonilla, A. (2014). América Latina y la nostalgia por la Guerra Fría. Recuperado en http://flacso.org/secretaria-general/am-rica-latina-y-nostalgia-guerra-fr consultado 30 de junio de 2016
} 
Vol.7, No 1. Diciembre de 2015 pp. $208-235$

un enemigo externo en América Latina, que los problemas de frontera son

mínimos y de poca monta. Entonces, los ejércitos para custodiar las fronteras no son necesarios porque ya no son los problemas de América Latina. Según esta doctrina la problemática de América Latina es la presencia de fuerzas subversivas orquestadas por la Unión Soviética, dirigidas desde Cuba que hacen necesario pensar en la reorganización de los ejércitos para contener la subversión. Esto se traduce en las Dictaduras y la forma como se va adoptar las estrategias con las cuales se hacen efectivas las la tortura las desapariciones.

La dictadura brasilera duro veinticinco años, empezando en 1961 luego se trasladó hacia Uruguay en 1971 y allí pasó a chile en 1973. Siguió su recorrido trasladándose en 1976 a Argentina y de esta forma el tiempo de las dictaduras del Cono Sur en América Latina se ha metido bajo la doctrina de la Seguridad Nacional del cual surge El Plan u Operación Cóndor ${ }^{18}$.

3.2. La influencia de la Dictadura en los posteriores sistemas de gobierno y la incidencia de la Guerra Fría en Brasil

La fecha de la creación (28 de noviembre 1975), en el marco de una reunión de seguridad presidida por Manuel Contreras - jefe de la policía secreta chilena- y en la que participaron militares de Argentina, Brasil, Bolivia, Paraguay y Uruguay, marcan los acontecimientos que en América latina se constituyeron en los inicios de las iniciativas por procurarse seguridad nacional, a la que los países del Cono Sur estaban urgidos. Según el Centro de Estudios Legales y Sociales

18 BBC Mundo. (2016) 4 claves para entender el Plan Cóndor, la empresa de la muerte creada por regímenes militares en Sudamérica http://www.bbc.com/mundo/america_latina/2016/05/160524_america_latina_plan_operacion_condor_argentin a_uruguay_bolivia_brasil_paraguay_jcps 
Vol.7, No 1. Diciembre de 2015 pp. $208-235$

(CELS) de Argentina, en realidad se trataba de una forma representada por un sistema de coordinación represiva entre los países del Cono Sur, el cual funcionó desde mediados de la década de los años 70 hasta iniciados los años 80 , con el propósito de perseguir y eliminar a militantes políticos, sociales, sindicales y estudiantiles de nacionalidad argentina, uruguaya, chilena, paraguaya, boliviana y brasileña.

En esta forma, personal de los servicios de seguridad de los países mencionados, cruzaron sin obstáculos las diferentes fronteras, cometiendo asesinatos, secuestros y torturas. De acuerdo con las investigaciones y denuncias, su accionar no se limitó a las seis naciones mencionadas: también se extendió a Italia y Estados Unidos. El papel que asumió los Estados Unidos de Norteamérica, ha sido muy controvertido, con diversas organizaciones de derechos humanos señalando que ese país - especialmente la CIA-, fueron los encargados de establecer el montaje desde el principio.

En un texto de la autoría del fallecido escritor inglés Christopher Hitchens, intitulado Juicio a Henry Kissinger ${ }^{19}$, hace referencia a la responsabilidad no sólo del exsecretario de Estado del país del norte, sino del involucramiento de agentes del FBI, lo cual aún permanece sin demostrar en un juicio, mientras que los protagonistas lo niegan. Lo que es indudable es que un plan así sólo era posible

\footnotetext{
${ }^{19}$ BBC Mundo. (2016). 4 claves para entender el Plan Cóndor, la empresa de la muerte creada por regímenes militares en Sudamérica. recuperado en

http://www.bbc.com/mundo/america_latina/2016/05/160524_america_latina_plan_operacion_condor_argentin a_uruguay_bolivia_brasil_paraguay_jcps consultado 30 de junio de 2016
} 
en el marco de la Guerra Fría, auspiciado por el fervor anticomunista de los regímenes militares existentes en América Latina.

La dictadura como pionero y como es un país que como Brasil ha logrado mayo prosperidad, el grueso de la doctrina de la seguridad nacional es seguido de cerca por la escuela de las Américas, son ellos los encargados de inventar las torturas, las desapariciones, la quema de libros, el cierre de las emisoras, las prohibiciones de las canciones, los exilios de los artistas, el movimiento popular, la dictadura, la toma contra los intelectuales de cualquier tendencia, independientemente de que estén involucrados o no a las dictadura; con el cierre de los espacios políticos en el Brasil, paraliza cualquier proceso de democratización.

Esto da pie para el surgimiento de los escuadrones de la muerte con el fin de sacar a las personas de sus casas y desaparecerlas y con ello se permite que se golpeen los derechos individuales y políticos, afectando de esta forma el desarrollo de una sociedad de confluencia política. Solo hasta el Siglo XX, en la era de Lula y durante los inicios del Siglo XXI que dieron origen a los balances históricos en los cuales por primera vez se hicieron elecciones directas, se ha pasado por un paso muy lento hacia la constitución de la democracia.

Con el golpe militar que depone a João Goular ${ }^{20} t$, se enfrían las ambiciones personales y partidarias de cualquier ideología y se instaura un régimen de excepción que perdurará oficialmente hasta 1985. Este régimen tuvo cinco

\footnotetext{
${ }^{20}$ EcuRed. Golpe de Estado al gobierno de Joao Goulart. Recuperado en http://www.ecured.cu/Golpe_de_estado_contra_Joao_Goulart. consultado el 30 de junio de 2016
} 
Vol.7, No 1. Diciembre de 2015 pp. $208-235$

presidentes, que si bien eran civiles al ejercer la presidencia, eran oficiales generales en reserva. Estos presidentes instalados en el solio del gobierno, fueron en orden cronológico: los mariscales Castelo Branco y Artur da Costa e Silva, y los generales Emílio Garrastazu Médici, Ernesto Geisel y João Baptista Figueiredo.

Bajo la influencia de técnicos como Eugênio Gudin, Roberto Campos y Antonio Delfim Netto, el régimen militar llevó a cabo reformas económicas, fiscales y estructurales, adoptando incluso algunas de las propuestas de João Goulart, como la reforma agraria y la nacionalización de empresas de infraestructuras, lo cual vislumbraba posibilidades de pensar por la vía de asegurar los bienes del estado..

La sociedad se presentó inicialmente entusiasta con el régimen por consecuencia del progreso económico, pero por la manipulación de los medios a través de la censura y la propaganda oficial, poco a poco este mismo pueblo se fue oponiendo al régimen autoritario. Las exageraciones del sistema de represión política, como la muerte del periodista y militante del Partido Comunista Brasileño (PCB) Vladimir Herzog, llevaron al propio Presidente de la nación, Ernesto Geisel a adoptar posiciones enérgicas contra la "línea dura", instaurada por su gobierno.

En las elecciones de 1976 la oposición tuvo un número creciente de votos, lo que llevó a una "lenta, segura y gradual" apertura política, en la cual se autorizaron la vuelta de varios exiliados políticos, el fin de la censura previa a la prensa, la amnistía y el movimiento de Diretas Já, de gran carga simbólica, que exigía las celebraciones de elecciones presidenciales directas, en vez de la elección indirecta que se realizó durante la mayor parte de la dictadura, pero que 
también hoy se percibe, como lo ocurrido con la quitada del poder a la actual mandataria Dilma Rousseff, considerado como un golpe de Estado.

3.3. El surgimiento de una democracia imperceptible en Brasil en términos de valores humanos

Con la llegada al poder de José Sarney $^{21}$ se instauró el nuevo régimen democrático en Brasil; este fue quien remplazo al primer presidente civil elegido desde el Golpe de Estado de 1964 (Tancredo Neves), el cual no llegó a asumir el cargo, víctima de unas complicaciones postoperatorias que le llevarían a la muerte, el 21 de abril de $1985^{22}$. Antes, el 15 de marzo, había asumido interinamente la presidencia José Sarney y luego de forma definitiva tras la muerte de Neves. En tal sentido, la democracia fue oficialmente restablecida en 1988 al promulgarse la actual Constitución Federal.

En el año 1989 fue elegido Fernando Collor de Mello $^{23}$, en representación del pequeño Partido da Renovação Nacional. Fue elegido Presidente en las primeras elecciones directas ocurridas en Brasil, después de 1964. Su gobierno duró desde 1989 hasta 1992, cuando decidió renunciar debido a un proceso de impugnación en su contra, ocasionado por una serie de denuncias que lo

${ }^{21}$ Ortiz de Z, R. (2016). Brasil Presidente de la República (1985-1990) y vicepresidente (1985) CIDOB. Recuperado en:

http://www.cidob.org/biografias_lideres_politicos/america_del_sur/brasil/jose_sarney consultado el $30 \mathrm{de}$ junio de 2016

${ }^{22}$ Goyzueta, V. (2015) Tancredo Neves, el presidente que no pudo asumir el poder. En ABC Internacional Recuperado en http://www.abc.es/internacional/20150422/abci-tancredo-neves-brasil201504220020.html consultado el 30 de junio de 2016

${ }^{23}$ Biografías. Fernando Collor de Mello. Recuperado en:

http://www.buscabiografias.com/biografia/verDetalle/4206/Fernando\%20Collor\%20de\%20Mello consultado el 30 de junio de 2016 
Vol.7, No 1. Diciembre de 2015 pp. $208-235$

envolvieron con casos de corrupción, la cual fue orquestada por el tesorero de su campaña electoral, Paulo César Farias. Asumió el cargo de Presidente en Brasil el Vicepresidente electo Itamar Franco, quien fue protagonista durante su período del surgimiento del Plan Real, articulado por su ministro de Hacienda, Fernando Henrique Cardoso. Este Plan Real, por su éxito, sería resorte político para que fuese elegido Presidente Cardoso, en 1994, a quien se reeligió en 1998.

En las elecciones efectuadas en el año 2002, el candidato opositor Luis Inácio Lula da Silva ${ }^{24}$, del Partido de los Trabajadores fue el vencedor del sucesor de Cardoso en el Partido Socialista de Brasil, PSDB, José Serra. Nuevamente se convertiría en presidente al propinarle la derrota cuatro años después (2006) a su opositor Geraldo Alckmin, también del PSDB.

En épocas reciente (2014), en la segunda ronda de las elecciones en Brasil, Dilma Rousseff ${ }^{25}$, sucesora de Lula da Silva al frente del Partido de los Trabajadores, fue elegida Presidente para el período 2015-2019, con lo cual se ha convertido en la primera mujer que ocupa este cargo en la nación con mejores niveles económicos y sociales del Cono Sur. Con su imposición al socialdemócrata José Serra se fortalece lo que se ha considerado como Nueva República (1985-presente), que se iniciaba como la continuidad de lo logrado por Lula da Silva, pese a los escándalos que hoy enfrenta desde el punto de vista político y que han sacudido y mantienen en una crisis de gobernabilidad al Estado

\footnotetext{
${ }^{24}$ Ortiz de Z, R. (2016). Brasil Presidente de la República (2003-2011). CIDOB. Recuperado en: http://www.cidob.org/biografias_lideres_politicos/america_del_sur/brasil/luiz_inacio_lula_da_silva consultado el 30 de junio de 2016

${ }^{25}$ Ortiz de Z, R. (2016). Brasil Presidenta de la República (2011-, en suspenso). CIDOB. Recuperado en: http://www.cidob.org/biografias_lideres_politicos/america_del_sur/brasil/dilma_rousseff consultado el 30 de junio de 2016
} 
Vol.7, No 1. Diciembre de 2015 pp. $208-235$

brasilero. Con la implementación de la democracia en el período anterior y la firme intención de su continuidad, y como una vuelta a resarcir los valores humanos a la población, el país se consolidaba en el plano internacional como un modelo a seguir.

Con la oposición en cabeza de su candidato Aécio Neves (PSDB) quien no reconoció las elecciones, se inició, por parte de políticos y gremios económicos, en cabeza de la poderosa Federação das Indústrias do Estado de São Paulo (FIESP)), una campaña para sacar al gobierno del poder por todos los medios posibles. Se realizaron demandas frente al Tribunal Supremo Electoral para impugnar las elecciones, y el único gran medio de comunicación (cadena O Globo) inició una intensa campaña contra el Gobierno, y fueron tejiéndose alianzas dentro de los representantes de la Cámara y del Senado para ser gobierno. El Gobierno elegido por el voto popular estaba conformado por una coalición hecha entre el PT y el $\mathrm{PMDB}^{26}$, buscando con ello ampliar y lograr una mayor y mejor gobernabilidad (en la medida que el PT no tiene mayorías en el Congreso).

No obstante al final, se produjo que frente a la fuerza de la oposición (representadas por grandes manifestaciones, el reacomodamiento de las fuerzas políticas y una crisis económica en todo el Estado), el partido de la coalición, el PMDB, cambiara en la alianza se dirigiera hacia la oposición con la que se alió y

\footnotetext{
${ }^{26}$ Se encuentran en la política brasilera una gran cantidad de partidos, pero en este artículo solo son nombrados los de mayor realce en la plataforma como los siguientes:: el Partido dos Trabalhadores PT, Partido Socialismo e Liberdade PSOL, Partido Comunista de Brasil PCdoB (de izquierda); el Partido do Movimento Democrático Brasileiro PMDB (centro-derecha); y Partido da Social Democracia Brasileira PSDB (derecha).
} 
Vol.7, No 1. Diciembre de 2015 pp. $208-235$

encabezó un nuevo gobierno que implementó el programa que perdió en las elecciones del pasado 2014 y que culminó con el triunfo de Dilma Rousseff.

Se dice que fue un golpe de Estado porque el Vicepresidente que asumió desde el pasado 12 de mayo no representaba el programa que fue elegido por 54.000.000 de votos en 2014. Una vez culminaron los debates, en medio de un pronunciado listado de trámites, se dieron las votaciones en la Cámara de Brasil (17 de abril de 2016), y el Senado (11 y 12 de mayo de 2016), las cuales culminaron con una primera etapa en la cual se suspendió del cargo a la Presidenta de la nación por 180 días, mientras el Senado realizaba el juicio político para su interrupción definitiva del mandato. Con la destitución de Rousseff, asumió el cargo el Vicepresidente Michel Temer, quien se alió para gobernar con el partido que perdió en las anteriores elecciones (PSDB).

En conclusión, el nuevo gobierno fue elegido indirectamente por el Congreso, y se construyó un nuevo Plan de Gobierno obligando al Partido de los Trabajadores (PT), que había sido elegido, a convertirse en oposición y con el cambio de slogan que pasó de "Brasil, Patria educadora" a "Brasil, Ordem e progresso", que daba cuenta de la intención del mensaje en procura de "recuperar el país de la desorganización política, económica y social y retomar el crecimiento económico"27. Al ser un gobierno elegido de manera indirecta, la mentalidad y los imaginarios en Brasil apuntaban a que este no se preocuparía por tomar medidas "populares"; puesto que su poder no proviene de la voluntad popular, sino de los

${ }^{27}$ Ese fue el slogan que implementó el actual Presidente Michel Temer para referirse al Governo Federal: Ordem e Progresso. 
Vol.7, No 1. Diciembre de 2015 pp. $208-235$

grupos que impulsaron el golpe de Estado, y por lo tanto la intencionalidad de estos se orientaba por el egoísmo y la búsqueda del poder, sobre todo, el militar, para asegurar su seguridad e intereses, lo que se denomina en la arena política internacional, anarquía en el orden mundial (poder, seguridad nacional e interés material), que hace que los Estados en esa búsqueda de la seguridad nacional, atenten contra otros Estados.

\section{Referencias.}

Abramo, Alcione. Grandes Personagens da Nossa História (v.1). São Paulo: Abril Cultural, 1969. (en portugués)

BBC Mundo. (2016). 4 claves para entender el Plan Cóndor, la empresa de la muerte creada por regímenes militares en Sudamérica. Recuperado en http://www.bbc.com/mundo/america_latina/2016/05/160524_america_latina _plan_operacion_condor_argentina_uruguay_bolivia_brasil_paraguay_jcps consultado 30 de junio de 2016

Benevides Mezquita, M.V. (1999). El Gobierno Quadros. 2ª edición Sao Paulo: Brasiliense,

Bergeon, L.; Furet, F. \& Koselleck, R. (1976). Historia Universal 26. La época de las Revoluciones Europeas 1780-1848. Madrid: Siglo XXI de España. 
Vol.7, No 1. Diciembre de 2015 pp. 208 -235

Biografías. Fernando Collor de Mello. Recuperado en:

http://www.buscabiografias.com/biografia/verDetalle/4206/Fernando\%20Coll or\%20de\%20Mello consultado el 30 de junio de 2016

Bonilla, A. (2014). América Latina y la nostalgia por la Guerra Fría. Recuperado en http://flacso.org/secretaria-general/am-rica-latina-y-nostalgia-guerra-fr consultado 30 de junio de 2016

Carone, E. (1974). A república nova, 1930-1937. São Paulo: Difusão Européia do Livro,

Carvalho, L. Gobierno Juscelino Kubitschek, Brasil School. Disponible en <http://brasilescola.uol.com.br/historiab/juscelino-kubitschek.htm>. Consultado el 30 de junio de 2016.

Conferencias Aliadas durante la Segunda GUERRA Mundial (2007). Recuperado en https://historia1imagen.cl/2007/09/11/conferencias-aliadas-durante-lasegunda-guerra-mudial/ consultado 30 de junio de 2016

EcuRed. Enrique el Navegante. Disponible en: http://www.ecured.cu/Enrique_el_Navegante Consultado el 22 de junio de 2016.

EcuRed. Golpe de Estado al gobierno de Joao Goulart. Recuperado en http://www.ecured.cu/Golpe_de_estado_contra_Joao_Goulart. Consultado el 30 de junio de 2016 
Ensayo de América Latina " Brasil". Recuperado en http://yazmin-

Vol.7, No 1. Diciembre de 2015 pp. $208-235$

alwaysthinkinme.blogspot.com.co/2011/03/ensayo-de-america-latina-

brasil.html Consultado el 25 de junio de 2016

Fausto, B. (2009). Historia de Brasil. Sao Paulo: Editora da Universidade de Sao Paulo.

Gómez Jaramillo, M. (2014). Las Independencias Hispanoamericanas.

Perspectivas Historiográficas españolas de 1808 a 1812. Madrid (España):

Universidad Carlos III de Madrid. Tesis Doctoral recuperado en:

http://earchivo.uc3m.es/bitstream/handle/10016/19042/tesis_marco_gomez\%20_jaramillo.pdf?sequen ce $=1$. Consultado el 25 de junio de 2016

Goyzueta, V. (2015) Tancredo Neves, el presidente que no pudo asumir el poder.

En ABC Internacional Recuperado en

http://www.abc.es/internacional/20150422/abci-tancredo-neves-brasil-

201504220020.html consultado el 30 de junio de 2016

Historia universal. Disponible en: http://www.historiacultural.com/2010/04/tratado-

de-tordesillas.html. Consultado el 22 de junio de 2016.

Historiaría Universal. El imperio de Brasil. Recuperado en

http://mihistoriauniversal.com/edad-contemporanea/imperio-de-brasil/.

Consultado el 25 de junio de 2016

http://www.bbc.com/mundo/america_latina/2016/05/160524_america_latina_plan_ operacion_condor_argentina_uruguay_bolivia_brasil_paraguay_jcps

Koifman, J. Compilador (2001), Presidentes do Brasil, Rio de Janeiro: Editora Rio. 
Vol.7, No 1. Diciembre de 2015 pp. 208 -235

Marina E. (2014) Brasil: la larga sombra de la dictadura. Recuperado

http://www.dw.com/es/brasil-la-larga-sombra-de-la-dictadura/a-17532308. consultado 30 de junio de 2016

Mejia Turizo, Jorge \& Medina Solano, Stephanie (2014) Arbitrariedad en las decisiones judiciales y administrativas, Revista JurídicaＥrg@omes, Vol.6 Num 1. Diciembre 2014.

Ortiz de Z, R. (2016). Brasil Presidenta de la República (2011-, en suspenso). CIDOB. Recuperado en: http://www.cidob.org/biografias_lideres_politicos/america_del_sur/brasil/dilm a_rousseff consultado el 30 de junio de 2016

Ortiz de Z, R. (2016). Brasil Presidente de la República (1985-1990) y vicepresidente (1985) CIDOB. Recuperado en: http://www.cidob.org/biografias_lideres_politicos/america_del_sur/brasil/jose _sarney consultado el 30 de junio de 2016

Ortiz de Z, R. (2016). Brasil Presidente de la República (2003-2011). CIDOB.

Recuperado en:

http://www.cidob.org/biografias_lideres_politicos/america_del_sur/brasil/luiz _inacio_lula_da_silva consultado el 30 de junio de 2016

Sanfuentes Echeverría, O. (2006). Europa y su percepción del nuevo mundo a través de las especies comestibles y los espacios americanos en el siglo XVI. Historia (Santiago). 2006, vol.39, n.2 Disponible en: 
Vol.7, No 1. Diciembre de 2015 pp. 208 -235

http://www.scielo.cl/scielo.php?script=sci_arttext\&pid=S0717-

71942006000200006 Consultado el 25 de junio de 2016 